\title{
Survey of High School Football Helmet Condition and Maintenance in Middle Tennessee
}

\author{
Thomas $\mathrm{MO}^{1 *}$, Allen $\mathrm{KS}^{1}$ and Alex $\mathrm{BD}^{2}$ \\ ${ }^{1}$ Department of Neurosurgery, Vanderbilt University Medical Center, Nashville, TN, USA \\ ${ }^{2}$ Department of Orthopaedic Surgery, Vanderbilt University Medical Center, Nashville, TN, USA
}

\section{Introduction}

Approximately 1.6-3.8 million mild traumatic brain injuries occur each year as a direct result of sports participation [1-6]. Football, particularly at the high school level, is the most common sport associated with these injuries [2]. As a collision sport, helmets are an important protective device [4]. Age, condition, and fit of football helmets are important factors in optimizing their protective properties.

We hypothesized that due to inconsistent staffing, a lack of resources, and decreased general awareness of the problem, high school athletic programs have suboptimal supervision and care of their helmet inventory thereby decreasing head-trauma related safety for their athletes. Further to this point, we hypothesized that helmets in private schools and suburban areas will be newer, better conditioned, and better inspected than helmets in rural and inner city areas. We undertook this study to investigate the current status of helmet testing, maintenance, and fitting in a cohort of high schools in Middle Tennessee.

\section{Methods}

We surveyed coaches and athletic trainers at 28 high schools in Davidson and Williamson Counties, Tennessee. Thirty high schools in the area were contacted individually and 28 agreed to participate. Surveys were administered individually to athletic trainers and coaches at each site. We gathered data on school demographics, number and type of current helmet inventory, fitting, age of inventory, record keeping practices, as well as inspection and recertification processes for the helmets at each school. Next, we performed onsite inspections of five random helmets at these schools using six criteria developed from guidelines by the National Operating Committee on Standards for Athletic Equipment (NOCSAE). These inspections were performed by one of the authors (TMO) after undergoing training with a collegiatelevel athletic trainer on assessment of helmet condition. Specifically, we looked for an up-to-date NOCSAE label, visible cracks in the shell, fully intact hardware, loosening or bending of the facemask, properly inflated air liners, and secure jaw pads to assess the overall condition of the sampled helmets.

The survey instruments were developed with input from collegiateand high school-level athletic trainers as well as experts within the realm of sports-related head injury. Data were compiled and pooled for analysis, including comparing public and private schools as well as urban and suburban schools. All data were analyzed using Stata version 13.0 (StataCorp LP, College Station, TX). Statistical tests included the Student t-test, chi-square, Fischer exact, and Wilcoxon rank-sum tests where appropriate. Statistical significance was defined as a p-value less than 0.05 , and applicable tests were two-sided.

\section{Results}

Twenty-one schools surveyed were public (75\%) and 7 were private (25\%). Fifteen schools were located in urban areas (53.6\%) and 13 were in suburban locations (46.4\%). There was a bimodal distribution of the average number of players at each school annually, with 10 schools reporting between 71-90 players and 5 schools reporting greater than 120 players. Five schools reported 70 players or fewer and the remaining 8 schools reported a number between 90 and 120. For public schools, the most frequently noted number of helmets in inventory was 91-100 (23.8\%). For private schools, the most frequently noted number of helmets in inventory was greater than $120(57.1 \%)$. This difference in average helmet inventory was statistically significant $(\mathrm{p}=0.039)$.

Twenty-five out of 28 schools (89.3\%) recertified all of their helmets annually, with an overall mean of $96.1 \%$ of helmets recertified each year in the entire cohort. There was no difference in percent of helmets sent in for reconditioning between public and private schools $(\mathrm{p}=0.43)$ or urban and suburban schools $(\mathrm{p}=0.80)$. The mean helmet age was 3.64 years and again no differences were noted between public and private schools $(\mathrm{p}=0.86)$ and between urban and suburban schools $(\mathrm{p}=0.16)$. The age of retirement of helmets was quite variable, with $22.2 \%$ of schools reporting a retirement age of 5 years, $18.5 \%$ reporting an age of 10 years, and $44.4 \%$ stating helmets were retired whenever they could no longer be recertified. No significant differences in helmet retirement policies were found between urban and suburban schools $(0.98)$ or between public and private schools $(\mathrm{p}=0.14)$.

Helmets were primarily fitted by coaches at 27 of the schools (96.4\%), with the athletic trainer responsible at the sole remaining school (3.6\%). The person responsible for fitting helmets was reported not to have particular certification to do so at 26 schools $(92.7 \%)$. Equipment managers were more common at private schools, present at $71.4 \%$ of private schools compared to $9.5 \%$ of public schools with this difference being significant $(\mathrm{p}=0.004)$. Players were allowed to provide their own helmets at $67.9 \%$ of schools, though at an overwhelming majority of these schools $10 \%$ of players or fewer chose to do so (89.5\%). Helmets were stored in climate-controlled environments at $66.7 \%$ of public schools and $100 \%$ of private schools, but this difference did not reach the threshold for statistical significance $(p=0.078)$. No written or computerized records were kept of the helmet inventory at $42.9 \%$ of schools, compared to written records at $33.3 \%$ of schools and computerized records at $23.8 \%$ of schools. The presence versus absence of any record of helmet inventory was not statistically significant between public and private schools $(\mathrm{p}=1.00)$. Similarly, there was no significant difference with regards to record keeping between urban

*Corresponding author: Thomas MO, Department of Neurosurgery, Vanderbilt University Medical Center, Nashville, TN, USA, Tel: +1 615-322-5000; E-mail: thomas. olynnger@vanderbilt.edu

Received February 23, 2015; Accepted March 21, 2015; Published March 23 , 2015

Citation: Thomas MO, Allen KS, Alex BD (2015) Survey of High School Footbal Helmet Condition and Maintenance in Middle Tennessee. J Trauma Treat 4:242. doi:10.4172/2167-1222.1000242

Copyright: (c) 2015 Thomas MO, et al. This is an open-access article distributed under the terms of the Creative Commons Attribution License, which permits unrestricted use, distribution, and reproduction in any medium, provided the original author and source are credited. 
and suburban schools $(\mathrm{p}=0.67)$.

The onsite visits evaluated helmets based on six criteria. A mean of 0.93 flaws per five helmets evaluated was noted at urban schools, compared to a mean of 1.54 flaws at suburban schools, though this difference was not significant $(p=0.20)$. Similarly, there was no significant difference in the mean number of flaws per five helmets noted between public and private schools ( 0.95 vs. $2, \mathrm{p}=0.17$ ). The most common flaw was a loose facemask, which was present in one or more of the five helmets evaluated at $53.6 \%$ of schools. A missing or out-ofdate NOCSAE label was the next most common flaw, present in one or more of the five helmets evaluated at $21.4 \%$ of schools. Overall, at least one flaw was present in at least one of the five helmets evaluated at $71.4 \%$ of schools in the cohort (Figure 1).

\section{Discussion}

We noted that helmets were similar overall at schools in Davidson and Williamson Counties, Tennessee. We had expected helmets in urban schools would be less well inspected and in poorer condition than helmets in suburban schools, but this was not the case due to a policy of Metropolitan Nashville Public Schools requiring 100\% helmet recertification each year. While suburban schools in Williamson County have greater resources, this policy serves to keep helmets on par despite more limited resources in urban areas. We noted that private schools tended to have more climate-controlled storage, equipment managers, and larger inventories compared to public schools. Despite stringent recertification policies, we noted a considerable lack of record keeping, with a large number of schools not using any form of record keeping whatsoever. Coaches and athletic trainers often responded that all of their helmets were recertified each year, but without documentation and accountability, this figure may be an unreliable estimate. Requiring written or computerized records of helmet age, condition, and date of recertification may help ensure helmets are properly documented and maintained.

Coaches are primarily responsible for fitting helmets at the vast majority of schools we surveyed. However, responsible individuals by and large had no formal training to properly fit helmets. This is a significant finding because while there are estimated to be over one million high school football players in the United States [5], very few individuals have standardized training on proper fitting guidelines. Formal training may be important to ensure helmets are properly fit to maximize their protective properties. Currently, there are no formal training programs outside of athletic trainer certification dealing specifically with proper equipment fitting. Given the high number of players engaged in high school football, as well as other contact sports, and the risk of traumatic brain injury, it may be beneficial to create an authority to certify individuals based on standardized equipmentfitting practices.

While helmets were in similar condition between public and private schools, it was striking to note that of the six criteria measured, at least one flaw was present in at least one of the five helmets evaluated at $71.4 \%$ of schools. This suggests that an estimated $20 \%$ of players may be wearing a helmet that does not meet current helmet inspection guidelines. Greater and more frequent inspection by coaches and athletic trainers may be required to ensure helmets continue to meet current guidelines during the season. Limitations of this study include its reliance on survey responses which are subject to bias and that results may not be generalizable to broader populations. Davidson and Williamson Counties lack significant rural areas and the strict

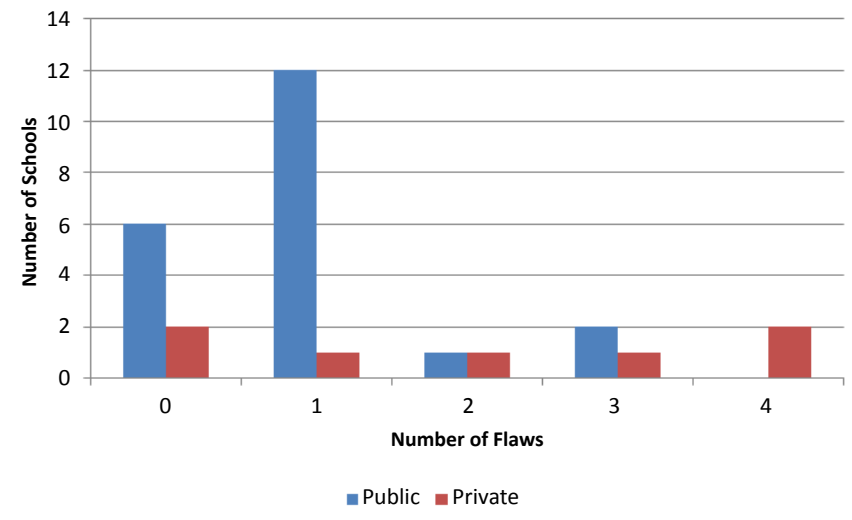

Figure 1: Number of flaws per five helmets evaluated.

recertification process found in Davidson County may not be common in other urban areas. Further analysis of urban and rural schools will help identify potential disparities in helmet maintenance and care. Additionally, though the survey instruments were designed with expert input to assess helmet condition and status, these instruments have not yet been validated.

\section{Conclusion}

Despite high rates of reconditioning, our survey revealed a surprisingly high number of flaws on direct inspection. Additionally, most helmets are fitted by personnel who lack formal training in proper technique. Record keeping of age and condition is also quite variable. These data suggest considerable opportunity to improve helmet fitting and maintenance which will lead to optimization of protective properties. In times of limited resources, this information will help guide individual schools and regulatory bodies as they establish policies, conduct educational events for their members, and allocate funding that is most meaningful. Our results highlight the current challenges of helmet maintenance, fit, and recertification for high school football programs.

\section{References}

1. Center for Disease Control and Prevention (2006) Traumatic Brain Injury.

2. National Center for Catastrophic Sport Injury Research (2013) University of North Carolina at Chapel Hill. Football Fatalities: 1-34.

3. National Federation of State High Schools Associations (2014) Participation Statistics.

4. McIntosh AS, Andersen TE, Bahr R, Greenwald R, Kleiven S, et al. (2011) Sports helmets now and in the future. Br J Sports Med 45: 1258-65.

5. National Center for Catastrophic Sport Injury (2013) Research University of North Carolina at Chapel Hill. All Sport Catastrophic Injuries.

6. Sosin DM, Sniezek JE, Thurman DJ (1996) Incidence of mild and moderate brain injury in the United States, 1991. Brain Inj 10: 47-54. 